\title{
Metabolic Control and Determinants Among HIV-Infected Type 2 Diabetes Mellitus Patients Attending a Tertiary Clinic in Botswana
}

This article was published in the following Dove Press journal: Diabetes, Metabolic Syndrome and Obesity: Targets and Therapy

\author{
Godfrey Mutashambara Rwegerera (iD) 1,2 \\ Dorothea HP Shailemo ${ }^{3}$ \\ Yordanka Pina Rivera iD ${ }^{4}$ \\ Kathryn O Mokgosi (iD 5 \\ Portia Bale ${ }^{6}$ \\ Taibat Aderonke Oyewo iD ${ }^{2,7}$ \\ Bruno Diaz Luis ${ }^{2}$ \\ Dereje Habte iD ${ }^{8}$ \\ Brian Godman (iD) ${ }^{9-11}$ \\ 'Department of Internal Medicine, \\ Faculty of Medicine, University of \\ Botswana, Gaborone, Botswana; \\ ${ }^{2}$ Department of Medicine, Princess \\ Marina Hospital, Gaborone, Botswana; \\ ${ }^{3}$ Department of Pharmacology and \\ Therapeutics, School of Pharmacy, \\ University of Namibia, Windhoek, \\ Namibia; ${ }^{4}$ Department of Medicine, \\ Sidilega Private Hospital, Gaborone, \\ Botswana; ${ }^{5}$ Department of Obstetrics \\ and Gynaecology, Nyangabgwe Referral \\ Hospital, Francistown, Botswana; ${ }^{6}$ Otse \\ Outpatient Clinic, District Health \\ Management Team, Lobatse, Botswana; \\ ${ }^{7}$ Department of Family Medicine, \\ University of Botswana, Gaborone, \\ Botswana; ${ }^{8}$ Consultant Public Health \\ Specialist, Addis Ababa, Ethiopia; ${ }^{9}$ School \\ of Pharmacy, Sefako Makgatho Health \\ Sciences University, Ga-Rankuwa, \\ Pretoria 0208, South Africa; ${ }^{10}$ Strathclyde \\ Institute of Pharmacy and Biomedical \\ Sciences, University of Strathclyde, \\ Glasgow G4 ORE, UK; "'Division of \\ Clinical Pharmacology, Karolinska \\ Institute, Karolinska University Hospital \\ Huddinge, Stockholm, Sweden
}

Correspondence: Godfrey Mutashambara Rwegerera

Department of Internal Medicine, Faculty of Medicine, University of Botswana, Corner of Notwane and Mobuto Road, Plot 4775,

Gaborone, Botswana

Tel +26775753207

Email grwege@yahoo.com
Purpose: We primarily aimed at determining the prevalence of metabolic syndrome and abnormal individual metabolic control variables in HIV-infected participants as compared to HIV-uninfected participants given current concerns. Our secondary objective was to determine the predictors of metabolic syndrome and individual metabolic control variables among the study participants to guide future management.

Patients and Methods: A descriptive, case-matched cross-sectional study for four months from 15th June 2019 to 15th October 2019 at Block 6 Diabetes Reference Clinic in Gaborone, Botswana. We compared the proportions of metabolic syndrome and individual metabolic control variables based on gender and HIV status by means of bivariate analysis (Chi-squared test or Fisher's exact test) to determine factors associated with metabolic control. A p-value of less than 0.05 was considered statistically significant.

Results: Overall, $86 \%$ of the study participants were found to have metabolic syndrome by International Diabetes Federation (IDF) criteria with 79.8\% among HIV-infected and 89.1\% among HIV-negative participants $(\mathrm{p}$-value $=0.018$ ). Older age was significantly associated with metabolic syndrome ( $\mathrm{p}$-value $=0.008$ ). Female gender was significantly associated with metabolic syndrome as compared to male gender (P-value $<0.001)$, and with a statistically significant higher proportion of low HDL-C compared to males (P-value $<0.001$ ). Female participants were significantly more likely to be obese as compared to males (P-value < 0.001). High triglycerides were more common in HIV-infected compared to HIV-negative participants $(\mathrm{P}$-value $=0.004)$. HIV-negative participants were more likely to be obese as compared to HIV-infected participants $(\mathrm{P}$-value $=0.003)$.

Conclusion: Metabolic syndrome is an appreciable problem in this tertiary clinic in Botswana for both HIV-infected and HIV-negative participants. Future prospective studies are warranted in our setting and similar sub-Saharan settings to enhance understanding of the role played by HAART in causing the metabolic syndrome, and the implications for future patient management.

Keywords: human immunodeficiency virus infection, HIV, diabetes mellitus, metabolic syndrome, sub-Saharan Africa, Botswana

\section{Introduction}

Diabetes Mellitus (DM) is a major public health concern worldwide and is rapidly increasing in sub-Saharan Africa, where it is projected to affect approximately 47 million people by 2045, almost three times the number in 2015. ${ }^{1,2}$ In Botswana, diabetes is also an emerging problem, and even when the real prevalence is currently unknown, current estimates indicate that at least $4.8 \%$ of adults aged $20-79$ years were affected by DM in 2017 , rising to $5.8 \%$ in $2019 ;^{3}$ an appreciable increase from $0.47 \%$ 
reported in 2004 by the International Diabetes Federation (IDF). ${ }^{4,5}$ This reflects growing concerns with the increased prevalence of DM across sub-Saharan Africa (SSA) increasing mortality rates, with an appreciable number of patients undiagnosed as well as sub-optimally managed. ${ }^{6,7}$ The care of patients with diabetes is multifaceted involving more than just glycemic control. Randomized controlled trials have demonstrated benefits from intensive control of blood pressure and lipids in patients with diabetes, leading to the formation of American Diabetic Association (ADA) goals for blood pressure and lipids. ${ }^{8,9}$

An interaction between infectious and noncommunicable diseases (NCDs) has become an emergent problem across SSA given the high prevalence rates of both and is creating additional challenges for health systems in SSA. ${ }^{10-12}$ The combination of DM and HIV infection represents a collision of two chronic conditions adversely affecting patients and healthcare systems in SSA and wider. ${ }^{13}$ Studies have shown an increase in poor glycemic control among DM patients who are HIVinfected with only $50-54 \%$ of them meeting the ADA HbA1c goal. ${ }^{13-16}$ Similarly, Davies found that only $46 \%$ of patients with both DM and HIV achieved the ADA HbAlc goal of 7\%. ${ }^{17}$ According to Satlin's crosssectional study where $33 \%$ of diabetic HIV-infected patients had inadequate glycemic control, factors associated with inadequate glycemic control included a more recent diagnosis of HIV, use of insulin or any diabetes medication, and higher triglyceride levels. ${ }^{9}$ Protease inhibitors (PI) use was associated with lower rates of meeting the ADA goal for HDL cholesterol among patients attending HIV clinics in New York, USA, whereas being male or not of African American ethnicity and use of an older Nucleoside Reverse Transcriptase Inhibitor (NRTI) were associated with lower rates of meeting the ADA goal for triglycerides. ${ }^{9}$ Previous global and regional studies have also shown that metabolic control among diabetic HIVinfected patients to be determined by both sociodemographic and economic factors; with age, body mass index, waist-hip ratio, central obesity and smoking being independently associated with metabolic disorders. $5,18-20$

The past few decades have resulted in appreciable improvements in the clinical outcomes of HIV-infected patients, mostly due to highly active antiretroviral therapy (HAART). Benefits of HAART include suppression of the viral load, improvement in CD4 count, decrease in opportunistic infections, reduction of length of hospital stay, and a reduction in mortality. ${ }^{21}$ However, the use of HAART has also resulted in an increase in metabolic dysfunction, including insulin resistance, diabetes, dyslipidemia and lipodystrophy. $^{22,23}$ Even before the availability of HAART, Grunfeld et al and others found that patients with AIDS had elevated plasma triglyceride and free fatty acid levels. ${ }^{24,25}$

Several studies have evaluated the lipid profile in diabetic HIV-infected patients and most of these have shown that less than $50 \%$ of patients achieve the goal of ADA related to HDL-cholesterol and triglycerides. ${ }^{9,15-17}$ Diabetic HIV-infected patients have unique potential cofactors for inadequate metabolic control including the use of specific antiretroviral medications such as nucleoside reverse transcriptase inhibitors (NRTIs) and Protease inhibitors (PIs). 9,26,27 Although the prevalence of inadequate metabolic control in the general diabetic population has been estimated in a large number of studies, ${ }^{28-33}$ only a few studies have estimated this prevalence in HIVinfected patients and most of them have assessed the achievement of ADA goal for glycemic control rather than comparing the metabolic control variables among groups of diabetic, HIV-infected and HIV-negative patients. ${ }^{9,14-17,28}$

According to the UNAIDS report of 2016, Botswana has the third highest HIV prevalence in the world with the latest reports estimating prevalence rates of $22.2 \%$ for the general population and $24 \%$ for 15 years and above age group. ${ }^{34}$ Botswana was the first African country to establish a National HIV Treatment Program and it has developed substantially over the last decade. ${ }^{27}$ The key characteristic is that care is universal and free, making antiretroviral treatment available to all eligible citizens. It was estimated that in 2015 approximately 264,000 adults living with HIV were receiving antiretroviral treatment in Botswana, a coverage of $78 \%$, up from $69 \%$ in $2013 .{ }^{34}$ With access to treatment, HIV-related mortality in Botswana has declined from $6 \%$ in 2003 to $1 \%$ in 2011, which is encouraging. ${ }^{34,35}$

However, in Botswana, where DM is a significant and growing health problem along with a known high burden of HIV infection, ${ }^{34}$ we are unaware of any documented research reporting prevalence and predictors of metabolic control among diabetic HIV-infected patients. We believe a better understanding will improve awareness of dual comorbidities and hence tailor scarce resources to the better management of patients with both diabetes and HIV infection in Botswana and among similar SSA countries with a double burden of DM and HIV-infection. This is 
particularly important at this time as the COVID-19 pandemic with various lockdown and other measures has negatively impacted on the care of patients with both infectious and non-infectious diseases across Africa and wider. ${ }^{36-38}$ Consequently, in the first instance, we principally sought to determine the prevalence of metabolic syndrome and abnormal individual metabolic control variables among HIV-infected patients in Botswana compared to HIV-negative patients. Our secondary objective was to determine the socio-demographic and clinical predictors of metabolic syndrome and individual metabolic control variables among study participants to guide future management.

\section{Patients and Methods}

\section{Study Design, Setting and Subjects}

A descriptive case-matched cross-sectional study was conducted from 15th June 2019 to 15th October 2019 at Block 6 Diabetes Reference clinic in Gaborone, Botswana. This is a leading clinic in Botswana offering various services to an estimated 3000 diabetic patients. Services include physician consultations, dietician, diabetes self-management, health education, eye and foot screening, laboratory services and the issuing of medicines. Within this population, cases were identified among patients with Type $2 \mathrm{DM}$ who were confirmed to be HIV-infected and on treatment and matched to similar cases in terms of gender but HIVnegative. Cases and matches were enrolled at a ratio of 1:2. The sample size was calculated by OpenEpi, Version 3, an open source calculator, by using Fleiss Statistical Methods for rates and proportion. ${ }^{39}$ The assumption used in the sample size calculation was a prevalence of $76.3 \%$ of glucose metabolic disorders among cases ${ }^{12}$ and a prevalence of $61.8 \%$ among the controls. ${ }^{40}$

With the intention of two-sided confidence-level (1-alpha) of $95 \%$ and power of $80 \%$ with a ratio of cases to control of 1:2, we estimated a minimum sample size for cases of HIV of 119 patients and 238 for control matches; with an estimated total sample size of 357 patients. The majority of enrolled participants were those who visited the clinic for physician consultations. Some patients were also recruited from the other services such as dietitians, eye clinic and nurse educators. Enrollment was undertaken on a daily basis from Monday to Friday. Routinely at block 6 clinic, physicians complete attendance sheets which include recent HIV status. Consequently, physicians consecutively identified patients who were HIV-infected and subsequently introduced the study and asked for their willingness to participate. Patients who agreed were subsequently directed to the research assistants for consenting and enrollment into the study.

For each identified case, each doctor identified two matches by gender and also referred them to the research assistants for consenting and enrollment. Inclusion criteria for this study involved having a documented diagnosis of type $2 \mathrm{DM}$ and documented results of HIV status in the past year. On the other hand, patients with type $1 \mathrm{DM}$, confirmed pregnancy, and those who did not consent were excluded from the study.

\section{Data Collection}

After signing an informed consent form, patients were interviewed by trained research assistants. A semistructured questionnaire was used with components adopted from the WHO STEPs questionnaire. ${ }^{41}$ Additional variables were subsequently included in the questionnaire. These included patients' demographic characteristics (age, gender, marital status and educational level) as well as clinical variables (durations of both diseases, ie, diabetes mellitus and HIV, modality of treatment for DM and antiretroviral (ARV) medication regimen (s) and duration).

All recruited patients had their blood pressure taken on the day of the interview using a digital blood pressure device while in a sitting position after a 10-minute rest period. This was performed before consultations. Anthropometric measurements including weight and height were also performed in order to calculate the body mass index (BMI) of patients using the following formula: weight (in Kilograms) divided by height squared $\left(\mathrm{m}^{2}\right)$. Waist and hip circumference were also measured to enable calculations of waist/hip ratio for categorizing their central obesity status. Research assistants involved in measuring weight, height, waist/hip circumference were oriented on standard measurement procedures before data collection was initiated.

\section{Laboratory Investigations}

Laboratory tests are undertaken routinely at block 6 clinic as a standard of care; consequently, patients did not incur any additional co-payment costs for these tests. These tests are usually performed in a non-fasting state at 3-6-month intervals. If patients' results of lipid profile \{total cholesterol, high-density lipoprotein (HDL), low-density lipoprotein (LDL) and triglycerides $\}$ and glycated hemoglobin 
(HbA1c) were available and within 3 months prior to data collection, they were recorded as current results; otherwise, patients were referred to the laboratory for venesection on the same day of the interview. Blood was collected at the block 6 clinic laboratory under aseptic techniques to obtain $5-10 \mathrm{ml}$ in plain tubes for the tests. The result of recent CD4 counts and viral load (for cases) were obtained from the electronic medical records and all the results were within 6 months of the day of the interview. Patients attending doctors' consultation were usually tested for either fasting blood glucose or post-prandial blood glucose (finger prick capillary blood test) routinely before they were attended; hence, these results were routinely available.

\section{Study Definitions}

The body mass index (BMI) was classified as either nonobese $\left(<30 \mathrm{~kg} / \mathrm{m}^{2}\right)$ or obese $\left(\geq 30 \mathrm{~kg} / \mathrm{m}^{2}\right)$ according to the WHO classification. ${ }^{42}$ The WHO STEPS protocol was adhered to with the waist circumference measurement made at the approximate midpoint between the lower margin of the last palpable rib and the top of the iliac crest whereas the hip circumference measurement was taken around the widest portion of the buttocks. ${ }^{43,44}$ According to the WHO classification, central obesity was defined as waist/hip ratio of $\geq 0.85$ for women and $\geq 0.90$ for men. ${ }^{45}$

Metabolic syndrome was categorized according to the new IDF criteria $^{46}$ which included waist circumference of $\geq 80 \mathrm{~cm}$ for women $/ \geq 94 \mathrm{~cm}$ for men plus at least two of the following:

Triglycerides $\geq 1.7$ or $\mathrm{HDL}<1.3$ for women $/ 1.0$ for men

\section{OR}

Systolic blood pressure (SBP) $\geq 130 \mathrm{mmHg}$ or Diastolic blood pressure (DBP) $\geq 85 \mathrm{mmHg}$ or being on treatment for hypertension

OR

Fasting blood glucose $>5.6 \mathrm{mmol} / \mathrm{l}$ or previous diagnosis of type 2 diabetes mellitus.

Individual metabolic control variables were defined according to American Diabetes Standard of Care 2019/ SEMDSA 2017 guidelines. ${ }^{47,48}$ The following indicated poor metabolic control: HbA1c $>7.0 \%$, LDL-C $>1.8$ $\mathrm{mmol} / 1$, HDL-C $<1.0$ for male and $<1.3 \mathrm{mmol} / 1$ for female, Triglycerides $>1.7 \mathrm{mmol} / 1$, total cholesterol $>4.5 \mathrm{mmol} / \mathrm{l}$, fasting blood glucose $>7.2 \mathrm{mmol} / \mathrm{l}$, postprandial glucose $>10.0 \mathrm{mmol} / \mathrm{l}$, Systolic blood pressure (SBP) $>140 \mathrm{mmHg}$, diastolic blood pressure (DBP) $>90 \mathrm{mmHg}$.

\section{Statistical Analysis}

Statistical Package for the Social Sciences (SPSS) software version 21 was used for data entry, cleaning and analysis. Frequency and percentages were used to describe the data. We compared the proportions of metabolic syndrome and individual metabolic control variables based on gender and HIV status by means of Chi-squared test or Fisher's exact test using bivariate analysis to determine factors associated with metabolic control. A p-value of less than 0.05 was considered statistically significant.

\section{Ethical Considerations}

Ethical clearance was obtained from the University of Botswana, Ministry of Health and Princess Marina Hospital Institutional Review Boards. The study adhered to the principles of the Declaration of Helsinki. ${ }^{49}$ The purpose of the study was fully explained to participants and they individually signed a written informed consent form administered in either Setswana or English, depending on which language the participant was comfortable with, prior to enrolment into the study. Patients received the standard of care and the study did not incur any costs to study participants. All participants were free to withdraw from the study at any time they wished to do so and this would not result in them receiving substandard care. To ensure patient confidentiality, the study participants were identified with unique identification numbers. Study information was stored in a secure cabinet at the University of Botswana and this was only accessible to the Principal Investigator.

\section{Results}

Studied socio-demographic and clinical characteristics including marital status, diabetes duration and history of hypertension and the use of lipid-lowering drugs were similar between HIV-infected and HIV-negative participants. There was though a significant difference in age categories between HIV-infected and HIV-negative participants $(\mathrm{P}$-value $=0.011)$. There was also a significant difference in the regimen of antidiabetic treatment with HIV-infected participants more likely to be on combined oral hypoglycemic medications and insulin therapy regimen as compared to HIV-negative participants $(37.0 \%$ versus $23.9 \%$, P-value $=0.020$ ) [Appendix Table 1].

Over half of the HIV-infected participants were diagnosed more than 10 years prior to the study $(56.3 \%)$. Almost all the HIV-infected participants, 118/119 
(99.2\%), were on HAART with $88.6 \%$ and $98.2 \%$ having CD4 counts of $\geq 350 \mathrm{umol} / 1$ and undetectable viral loads, respectively. The rest of the characteristics of studied HIVinfected participants are depicted in [Table 1].

Overall, $86 \%$ of the study participants were found to have metabolic syndrome by IDF criteria. The difference in proportions of metabolic syndrome between HIVinfected $(79.8 \%)$ and HIV negative $(89.1 \%)$ participants was statistically significant $(\mathrm{P}$-value $=0.018)$ [Table 2].

Age was significantly associated with metabolic syndrome $(\mathrm{P}$-value $=0.008)$ with proportions with metabolic syndrome for age group $\geq 40$ years ranging between $87.4 \%$ $-89.7 \%$ compared to $67.6 \%$ for the age group $<40$ years. Female gender was significantly associated with metabolic syndrome as compared to males (95.2\% versus $69.0 \%$ ) (P-value $<0.001$ ). Marital status, level of education, and diabetes duration were similar between participants with/ without the metabolic syndrome. HIV-infected participants with a shorter duration since HIV diagnosis (0-9 years) were more likely to have the metabolic syndrome $(88.9 \%$ $92.3 \%$ ) compared to those with a longer duration since HIV diagnosis of $\geq 10$ years $(67.9 \%-76.7 \%)$. However, the duration since HIV diagnosis was not statistically associated with metabolic syndrome $(\mathrm{P}$-value $=0.056)$. Other HIV-infection characteristics including the duration of HIV treatment, CD4 count, and viral load count, as well as the use of protease inhibitors, integrase inhibitors and NNRTIs, were similar between participants with/without the metabolic syndrome [Table 3].

Female gender showed a significantly higher proportion of low HDL-C compared to males $(76.6 \%$ versus $50.5 \%$ ) (P-value $<0.001$ ). Female participants were significantly more likely to be obese as compared to males $(60.8 \%$ versus $19.4 \%$, P-value $<0.001)$. On the other hand, male gender was associated with a higher proportion of participants with elevated diastolic blood pressure compared to females $(25.6 \%$ versus $11.7 \%$, P-value $=0.001)$. As for glycemic control using HbA1c, 53.2\% and $60.6 \%$ of male and female participants, respectively, had poor control with the difference not statistically significant. Central obesity was one of the commonest findings in both males and females accounting for $76.8 \%$ and $82.8 \%$, respectively. The rest of the analyzed individual metabolic control variables including LDL-C, triglycerides, total cholesterol, and systolic blood pressure were similar between male and female participants [Table 4].

High triglyceride levels were more common in HIVinfected compared to HIV-negative participants $(68.9 \%$ versus $51.4 \%$, P-value $=0.004)$. On the other hand, HIVnegative participants $(52.5 \%)$ were more likely to be obese (high body mass index) as compared to HIV-infected participants $(34.9 \%, \mathrm{P}$-value $=0.003)$. HIV-infected participants had higher proportions of central obesity $(87.4 \%)$ as compared to HIV-negative participants (77.3\%). The difference was however not statistically significant $(p$-value $=0.057)$. The HIV-infected group had higher proportions of participants with both high fasting blood glucose and postprandial blood glucose compared to the HIV-negative group; however, the difference was not statistically significant. The rest of the individual metabolic control variables were similar between HIV-infected and HIV-negative participants [Table 5].

\section{Discussion}

We believe this is one of the first studies that has evaluated the prevalence and factors associated with metabolic syndrome in diabetic patients with HIV-infection in a country with a high prevalence of both HIV and diabetes. The published literature is rich with studies of either metabolic syndrome in HIV-infected participants or metabolic syndrome in diabetic participants; however, not the combination. We found a very high overall prevalence of metabolic syndrome of $86 \%$ in our participants regardless of their HIV status. In addition, the prevalence of metabolic syndrome was significantly higher in HIV-negative participants $(89.1 \%)$ as compared to HIV-infected participants (79.8\%). Previous studies in Africa have estimated a prevalence of metabolic syndrome among HIV-infected participants ranging from $13 \%$ to $58 \% .^{50,51}$ We did not find studies on the prevalence of metabolic syndrome among diabetic patients in Africa; however, studies in India revealed a prevalence of metabolic syndrome ranging from $71.9 \%$ to $73.85 \% .{ }^{52,53}$ Due to the fact that both HIV-infection and DM are pro-inflammatory conditions associated with metabolic disturbances including but not limited to insulin resistance and lipoprotein disturbances, a high prevalence of metabolic syndrome was expected. The fact that metabolic syndrome was highest among HIVnegative diabetic participants emphasizes the need to look closely at individual factors that impact on metabolic syndrome in this group.

Older age was significantly associated with metabolic syndrome similar to several previous studies. ${ }^{54-58}$ Female HIV-infected diabetic participants were significantly more likely to have metabolic syndrome compared with their male counterparts; a finding that has been consistently 
Table I Clinical Characteristics of HIV-Infected Participants

\begin{tabular}{|c|c|}
\hline Variables & Frequency, n (\%) \\
\hline \multicolumn{2}{|l|}{ HIV duration in years } \\
\hline $0-4$ & $26(21.8 \%)$ \\
\hline $5-9$ & $26(21.8 \%)$ \\
\hline $10-14$ & 37 (31.1\%) \\
\hline $15+$ & $30(25.2 \%)$ \\
\hline \multicolumn{2}{|l|}{ HIV treatment duration in years } \\
\hline $0-4$ & $39(32.8 \%)$ \\
\hline $5-9$ & $29(24.4 \%)$ \\
\hline $10-14$ & $25(21.0)$ \\
\hline $15+$ & $26(21.8 \%)$ \\
\hline \multicolumn{2}{|l|}{ HAART treatment status } \\
\hline Yes & 118 (99.2\%) \\
\hline No & I (0.8\%) \\
\hline \multicolumn{2}{|l|}{ Initial HAART regimen } \\
\hline Truvada + Efavirenz & $51(43.6 \%)$ \\
\hline Combivir + Efavirenz & $30(25.6 \%)$ \\
\hline Combivir + Nevirapine & $18(15.4 \%)$ \\
\hline Truvada + Dolutegravir & $12(10.3 \%)$ \\
\hline Others* & $6(5.3 \%)$ \\
\hline \multicolumn{2}{|l|}{ Current HAART regimen } \\
\hline Truvada + Efavirenz & $48(41.0 \%)$ \\
\hline Combivir + Efavirenz & $23(19.7 \%)$ \\
\hline Combivir + Nevirapine & $12(10.3 \%)$ \\
\hline Truvada + Dolutegravir & $20(17.1 \%)$ \\
\hline Abacavir + Lamivudine + Dolutegravir & $9(7.7 \%)$ \\
\hline Others* & $5(4.4 \%)$ \\
\hline \multicolumn{2}{|l|}{ CD4 count } \\
\hline$<350$ & 13 (1 I.4\%) \\
\hline $350-500$ & $23(20.2 \%)$ \\
\hline$>500$ & 78 (68.4\%) \\
\hline \multicolumn{2}{|l|}{ Viral Load } \\
\hline Suppressed & III (98.2\%) \\
\hline Not Suppressed & $2(1.8 \%)$ \\
\hline \multicolumn{2}{|l|}{ Protease inhibitor use } \\
\hline Yes & $2(1.7 \%)$ \\
\hline No & 113 (98.3\%) \\
\hline \multicolumn{2}{|l|}{ Integrase inhibitor (DTG) use } \\
\hline Yes & $27(23.5 \%)$ \\
\hline No & $88(76.5 \%)$ \\
\hline \multicolumn{2}{|l|}{ NNRTI (Efavirenz or Nevirapine) use } \\
\hline Yes & 87 (74.4\%) \\
\hline No & $30(25.6 \%)$ \\
\hline
\end{tabular}

Note: Others*, refers to Truvada+ Nevirapine; Truvada+ Lopinavir/Ritonavir; Truvada+ Dolutegravir; Abacavir+ Lamivudine+ Nevirapine; Abacavir+Lamivudine + Efavirenz; Abacavir+Lamivudine+ Dolutegravir.

found in previous studies. ${ }^{52,56-58} \mathrm{HIV}$-infected participants had a significantly lower prevalence of obesity as
Table 2 Metabolic Syndrome Using IDF Criteria According to HIV Status

\begin{tabular}{|l|l|l|l|}
\hline \multirow{2}{*}{ Variables } & \multicolumn{2}{|l|}{ Metabolic Syndrome } & \multirow{2}{*}{ p-value } \\
\cline { 2 - 3 } & Yes & No & \\
\hline HIV status & & & \\
Positive & $95(79.8 \%)$ & $24(20.2 \%)$ & $\mathbf{0 . 0 1 8}$ \\
Negative & $212(89.1 \%)$ & $26(10.9 \%)$ & \\
Total & $\mathbf{3 0 7}(\mathbf{8 6 . 0 \% )}$ & $50(14.0 \%)$ & \\
\hline
\end{tabular}

Note: Bold indicates statistical significance.

compared to HIV-negative participants, a finding similar to a study by Mondy et al in the US. ${ }^{54}$

We found the prevalence of the metabolic syndrome to be highest during the early years of HIV diagnosis compared to later years. The difference did not reach statistical significance. Given the limitation of our study design, it is difficult to explain whether the metabolic syndrome was present before the initiation of HAART. It is possible that HAART played a part in the development of the metabolic syndrome as most patients are initiated on HAART at diagnosis, and we will be looking at this more closely in future prospective projects. Our results are similar to findings of other studies in SSA that revealed a higher prevalence of metabolic disorders after HAART initiation. $^{59,60}$

Different classes of HAART including nucleoside reverse transcriptase inhibitors (NRTIs) and protease inhibitors (PIs) have been shown to cause the metabolic syndrome through mechanisms such as increasing insulin resistance, reducing insulin secretion, interfering with glucose transporter type 4-mediated glucose transport, lipodystrophy, alteration in leptin/adiponectin dynamics and mitochondrial dysfunction. ${ }^{27,61}$ The PIs have also been shown to interfere with cellular retinoic acid-binding protein type 1 (CRAB-1) which in turn inhibits peroxisomal proliferator-activated receptor $\gamma$ (PPAR $\gamma)$. The inhibition of PPAR $\gamma$ leads to insulin resistance and the release of free fatty acids. ${ }^{27}$ The prescribing of PIs was not though associated with the metabolic syndrome in our study, similar to a previous study. ${ }^{12}$ We believe this can be explained by the small sample size as only $2 / 116(1.7 \%)$ of our participants were on PIs. On the other hand, the majority of our HIVinfected participants had been on NRTI regimens containing tenofovir as it is currently part of first-line treatment for HIV patients in Botswana. ${ }^{62}$ This may partly explain the lack of association between metabolic syndrome and NRTIs for patients who had been exposed to HAART for 
Table 3 Predictors of Metabolic Syndrome (IDF Criteria) Among Study Participants

\begin{tabular}{|c|c|c|c|}
\hline \multirow[t]{2}{*}{ Variables } & \multicolumn{2}{|c|}{ Metabolic Syndrome } & \multirow[t]{2}{*}{ p-value } \\
\hline & Yes & No & \\
\hline \multicolumn{4}{|l|}{ Age } \\
\hline $21-40$ & $25(67.6 \%)$ & $12(32.4 \%)$ & 0.008 \\
\hline $4 I-50$ & $70(89.7 \%)$ & $8(10.3 \%)$ & \\
\hline $5 I-60$ & $104(87.4 \%)$ & $15(12.6 \%)$ & \\
\hline $60+$ & $108(87.8 \%)$ & $15(12.2 \%)$ & \\
\hline \multicolumn{4}{|l|}{ Gender } \\
\hline Male & $87(69.0 \%)$ & $39(31.0 \%)$ & $<0.001$ \\
\hline Female & $220(95.2 \%)$ & II (4.8\%) & \\
\hline \multicolumn{4}{|l|}{ Level of education } \\
\hline No formal school & $36(87.8 \%)$ & $5(12.2 \%)$ & 0.717 \\
\hline Less than primary education & $35(79.5 \%)$ & $9(20.5 \%)$ & \\
\hline Primary school completed & $71(86.6 \%)$ & II (I3.4\%) & \\
\hline Secondary school completed & $109(87.9 \%)$ & $15(12.1 \%)$ & \\
\hline College/University/Post-graduate degree & $56(84.8 \%)$ & $10(15.2 \%)$ & \\
\hline \multicolumn{4}{|l|}{ Marital status } \\
\hline Never married & $126(86.9 \%)$ & $19(13.1 \%)$ & 0.771 \\
\hline Currently married & $127(83.6 \%)$ & $25(16.4 \%)$ & \\
\hline Separated & I (I00.0\%) & $0(0.0 \%)$ & \\
\hline Divorced & 8 (88.9\%) & I (II.I\%) & \\
\hline Widowed & $39(90.7 \%)$ & $4(9.3 \%)$ & \\
\hline Cohabiting & $4(100.0 \%)$ & $0(0.0 \%)$ & \\
\hline \multicolumn{4}{|l|}{ Diabetes duration in years } \\
\hline Less than 2 & 60 (77.9\%) & $17(22.1 \%)$ & 0.118 \\
\hline $2-5$ & $92(86.8 \%)$ & 14 (I3.2\%) & \\
\hline $6-10$ & $78(90.7 \%)$ & $8(9.3 \%)$ & \\
\hline II or more & $75(87.2 \%)$ & II (I2.8\%) & \\
\hline \multicolumn{4}{|l|}{ HIV duration in years } \\
\hline $0-4$ & $24(88.9 \%)$ & $3(11.1 \%)$ & 0.056 \\
\hline $5-9$ & $24(92.3 \%)$ & $2(7.7 \%)$ & \\
\hline $10-14$ & $25(67.9 \%)$ & $12(32.4 \%)$ & \\
\hline $15+$ & $23(76.7 \%)$ & 7 (23.2\%) & \\
\hline \multicolumn{4}{|l|}{ HIV treatment duration in years } \\
\hline $0-4$ & $34(85.0 \%)$ & $6(15.0 \%)$ & 0.650 \\
\hline $5-9$ & $23(79.3 \%)$ & $6(20.7 \%)$ & \\
\hline $10-14$ & $18(72.0 \%)$ & 7 (28.0\%) & \\
\hline $15+$ & $21(80.8 \%)$ & 5 (19.2\%) & \\
\hline \multicolumn{4}{|l|}{ CD4 count } \\
\hline$<350$ & $8(61.5 \%)$ & $5(38.5 \%)$ & 0.189 \\
\hline $350-500$ & $18(78.3 \%)$ & $5(21.7 \%)$ & \\
\hline$>500$ & $65(83.3 \%)$ & $13(16.7 \%)$ & \\
\hline \multicolumn{4}{|l|}{ Protease inhibitor use } \\
\hline Yes & $2(100.0 \%)$ & $0(0.0 \%)$ & 0.466 \\
\hline No & $90(78.9 \%)$ & $24(21.1 \%)$ & \\
\hline
\end{tabular}

(Continued) 
Table 3 (Continued).

\begin{tabular}{|l|l|l|}
\hline Variables & Metabolic Syndrome & No \\
\cline { 2 - 4 } & Yes & \\
\hline Integrase inhibitor (DTG) use & & $\begin{array}{l}8(29.6 \%) \\
16(18.0 \%)\end{array}$ \\
Yes & $19(70.4 \%)$ & \\
No & $73(82.0 \%)$ & $16(18.4 \%)$ \\
\hline NNRTI (Efavirenz or Nevirapine) use & & $8(25.8 \%)$ \\
Yes & $71(81.6 \%)$ & 0.190 \\
No & $23(74.2 \%)$ & 0.378 \\
\hline
\end{tabular}

Note: Bold indicates statistical significance.

a longer duration in our study. Previous studies have also associated older regimens of NRTIs such as stavudine, zidovudine and didanosine with the prevalence of the metabolic syndrome; ${ }^{61}$ with the effect noticeably after a longer exposure. However, this is not the case in Botswana as the guideline stipulates patients should be initiated on tenofovir-containing regimens unless there are contraindications. We did not find any association between the use of NNRTIs and the occurrence of the metabolic syndrome; similar to a previous study in the US. ${ }^{54}$ Dolutegravir (DTG) which is an integrase inhibitor was introduced to HIV treatment guidelines in Botswana in 2016. ${ }^{62}$ Previous studies comparing DTG to NNRTIs and PIs revealed that the former has more of a neutral effect on causing lipid abnormalities and it was only associated with more weight gain. ${ }^{15,63}$ About a quarter of our HIV-infected participants were on DTG-containing regimen and we did not find an association between the use of DTG and the metabolic syndrome. However, this finding needs to be interpreted with caution given the shorter duration of its use in Botswana. Future studies are needed to fully assess the effect of DTG on metabolic control after a longer exposure period to establish whether the previous established weight gain effect has a role to play in the development of the metabolic syndrome in patients with HIV, and we will be following this up in future studies.

We did not find any difference in the level of glycemic control between HIV-infected and HIV-negative participants, which was also observed in previous studies in SSA $;{ }^{18,64}$ however, $57.1 \%$ of the HIV-infected diabetic participants had poor glycemic control in our study as compared to $33 \%$ and $46 \%$ from studies in Tanzania and Nigeria, respectively. ${ }^{18,64}$ We found that $58.1 \%$ of HIVnegative diabetic participants had poor glycemic control, in contrast to findings of US studies that had $44 \%$ and $24 \%$ of patients with poor glycemic control. ${ }^{65}$ This variation may be explained by differences in patients' characteristics and differences in cut-off points for glycemic control with the Tanzania study using a $7.5 \%$ cut-off point while we used the ADA cut-off point of $7 \%$. On the other hand, there was a significant difference among HIV-infected and HIV-negative participants on types of antidiabetic treatment prescribed, with the former group having a large number of patients on combination therapy of oral hypoglycemic agents together with insulin therapy. It is possible that HIV-infected participants had presented with poorer glycemic control levels necessitating insulin initiation, which ultimately resulted in seemingly similar levels of glycemic control with HIV-negative participants. This though remains to be shown.

Our results showing higher proportions of elevated fasting blood glucose (FBG) and post-prandial blood glucose (PPBG) are similar to the results of a prospective study by Zannou et al which showed similar trends after 24 months of follow up. ${ }^{59}$ Similar trends have been observed in cross-sectional studies undertaken in the United States of America. ${ }^{66,67}$ The results of this study are similar to those of Maganga et al in Tanzania ${ }^{18}$ but differ from similar studies in other SSA countries which showed no differences in glucose measurements between HIV-infected and HIVnegative participants. ${ }^{16,68,69}$ The possible reasons for the discrepancies between the various studies include differences in patients' characteristics and methods used for assessing glucose levels. The higher proportions of higher FBG and PPBG in our HIV-infected group may be related to immune reconstitution from the use of HAART as there was a trend of increasing metabolic syndrome (FBG being a component) with higher CD4 
Table 4 Characteristics of Individual Metabolic Control Variables Classified from ADA Criteria According to Gender

\begin{tabular}{|c|c|c|c|}
\hline Characteristics & Male & Female & p-value \\
\hline \multicolumn{4}{|c|}{ Glycemic control (HbAlc) } \\
\hline Good control ( $\leq 7 \%)$ & 59 (46.8\%) & 91 (39.4\%) & 0.174 \\
\hline Poor control (>7\%) & $67(53.2 \%)$ & $140(60.6 \%$ & \\
\hline \multicolumn{4}{|l|}{ Central obesity } \\
\hline Yes & 96 (76.8\%) & I 88 (82.8\%) & 0.159 \\
\hline No & $29(23.2 \%)$ & $39(17.2 \%)$ & \\
\hline \multicolumn{4}{|l|}{ LDL-C } \\
\hline Normal & 15 (I8.5\%) & $23(15.9 \%)$ & 0.609 \\
\hline High & $66(81.5 \%)$ & $122(84.1 \%)$ & \\
\hline \multicolumn{4}{|l|}{ HDL-C } \\
\hline Low & $48(50.5 \%)$ & |4| (76.6\%) & $<0.001$ \\
\hline Normal & 47 (49.5\%) & $43(23.4 \%)$ & \\
\hline \multicolumn{4}{|l|}{ Triglycerides } \\
\hline Normal & $43(42.2 \%)$ & $75(42.1 \%)$ & 0.997 \\
\hline High & 59 (57.8\%) & $103(57.9 \%)$ & \\
\hline \multicolumn{4}{|l|}{ Total cholesterol } \\
\hline Normal & $84(68.3 \%)$ & $146(64.6 \%)$ & 0.487 \\
\hline High & $39(31.7 \%)$ & $80(35.4 \%)$ & \\
\hline \multicolumn{4}{|l|}{ Fasting Blood Glucose } \\
\hline Normal & $5(62.5 \%)$ & $5(62.5 \%)$ & 1.000 \\
\hline High & $3(37.5 \%)$ & $3(37.5 \%)$ & \\
\hline \multicolumn{4}{|c|}{ Post-prandial blood glucose } \\
\hline Normal & $73(62.9 \%)$ & $139(64.4 \%)$ & 0.797 \\
\hline High & 43 (37.1\%) & 77 (35.6\%) & \\
\hline \multicolumn{4}{|l|}{ Systolic blood pressure } \\
\hline Normal & $70(56.0 \%)$ & $142(61.5 \%)$ & 0.315 \\
\hline High & 55 (44.0\%) & 89 (38.5\%) & \\
\hline \multicolumn{4}{|l|}{ Diastolic blood pressure } \\
\hline Normal & $93(74.4)$ & $204(88.3 \%)$ & 0.001 \\
\hline High & $32(25.6 \%)$ & 27 (II.7\%) & \\
\hline \multicolumn{4}{|l|}{ Body mass index (BMI) } \\
\hline Non-obese & 87 (80.6\%) & 78 (39.2\%) & $<0.001$ \\
\hline Obese & 21 (19.4\%) & 121 (60.8\%) & \\
\hline
\end{tabular}

Note: Bold indicates statistical significance.

counts though this did not reach statistical significance (p-value $=0.189)$. With our HIV-infected participants being largely HAART experienced, the role of HAART cannot be excluded and needs to be investigated in future prospective studies in Botswana.

Diabetes mellitus (DM) and HIV-infection are both known to be pro-inflammatory conditions with metabolic disturbances such as defective lipoprotein metabolism resulting in hypertriglyceridemia, hypercholesterolemia and low serum high-density lipoprotein.
(HDL) cholesterol. ${ }^{8,24}$ The same observation was made in our study whereby HIV-infected participants were found to have high degrees of dyslipidemia of $39.3 \%, 67.7 \%$ and $68.9 \%$ for hypercholesterolemia, low serum high-density lipoprotein (HDL) cholesterol, and hypertriglyceridemia, respectively, according to ADA criteria. These findings are similar to those of Maganga et al in Tanzania. ${ }^{18}$ A very small proportion of our participants achieved target levels of low-density lipoprotein cholesterol (LDL-C) with $14.4 \%$ and $18.4 \%$ in HIV-infected and HIV-negative 
Table 5 Characteristics of Individual Metabolic Control Variables Classified from ADA Criteria According to HIV Status

\begin{tabular}{|c|c|c|c|}
\hline Characteristics & $\begin{array}{l}\text { HIV- } \\
\text { Infected }\end{array}$ & $\begin{array}{l}\text { HIV- } \\
\text { Negative }\end{array}$ & p-value \\
\hline $\begin{array}{l}\text { Glycemic control (HbA|c) } \\
\text { Good control ( } \leq 7 \%) \\
\text { Poor control }(>7 \%)\end{array}$ & $\begin{array}{l}5 I \text { ( } 42.9 \%) \\
68(57.1 \%)\end{array}$ & $\begin{array}{l}99(41.6 \%) \\
139(58.4 \%)\end{array}$ & 0.820 \\
\hline $\begin{array}{l}\text { Central obesity } \\
\text { Yes } \\
\text { No }\end{array}$ & $\begin{array}{l}104(87.4 \%) \\
15(12.6 \%)\end{array}$ & $\begin{array}{l}180(77.3 \%) \\
53(22.7 \%)\end{array}$ & 0.057 \\
\hline $\begin{array}{l}\text { LDL-C } \\
\text { Normal } \\
\text { High }\end{array}$ & $\begin{array}{l}13(14.4 \%) \\
77(85.6 \%)\end{array}$ & $\begin{array}{l}25 \text { (18.4\%) } \\
\text { III (8I.6\%) }\end{array}$ & 0.438 \\
\hline $\begin{array}{l}\text { HDL-C } \\
\text { Low } \\
\text { Normal }\end{array}$ & $\begin{array}{l}65(67.7 \%) \\
31 \text { (32.3\%) }\end{array}$ & $\begin{array}{l}124(67.8 \%) \\
59(32.2 \%)\end{array}$ & 0.993 \\
\hline $\begin{array}{l}\text { Triglycerides } \\
\text { Normal } \\
\text { High }\end{array}$ & $\begin{array}{l}32(31.1 \%) \\
71(68.9 \%)\end{array}$ & $\begin{array}{l}86 \text { (48.6\%) } \\
91 \text { (51.4\%) }\end{array}$ & 0.004 \\
\hline $\begin{array}{l}\text { Total cholesterol } \\
\text { Normal } \\
\text { High }\end{array}$ & $\begin{array}{l}7 \mid(60.7 \%) \\
46(39.3 \%)\end{array}$ & $\begin{array}{l}159 \text { (68.5\%) } \\
73(31.5 \%)\end{array}$ & 0.144 \\
\hline $\begin{array}{l}\text { Fasting Blood Glucose } \\
\text { Normal } \\
\text { High }\end{array}$ & $\begin{array}{l}3(50.0 \%) \\
3(50.0 \%)\end{array}$ & $\begin{array}{l}7(70.0 \%) \\
3(30.0 \%)\end{array}$ & 0.424 \\
\hline $\begin{array}{l}\text { Post-prandial blood } \\
\text { glucose } \\
\text { Normal } \\
\text { High }\end{array}$ & $\begin{array}{l}63(56.8 \%) \\
48(43.2 \%)\end{array}$ & $\begin{array}{l}149 \text { (67.4\%) } \\
72(32.6 \%)\end{array}$ & 0.056 \\
\hline $\begin{array}{l}\text { Systolic blood pressure } \\
\text { Normal } \\
\text { High }\end{array}$ & $\begin{array}{l}69(58.5 \%) \\
49(41.5 \%)\end{array}$ & $\begin{array}{l}143(60.1 \%) \\
95 \text { (39.9\%) }\end{array}$ & 0.771 \\
\hline $\begin{array}{l}\text { Diastolic blood pressure } \\
\text { Normal } \\
\text { High }\end{array}$ & $\begin{array}{l}100(84.7 \%) \\
18(15.3 \%)\end{array}$ & $\begin{array}{l}197(82.8 \%) \\
41 \text { (17.2\%) }\end{array}$ & 0.638 \\
\hline $\begin{array}{l}\text { Body mass index (BMI) } \\
\text { Non-obese } \\
\text { Obese }\end{array}$ & $\begin{array}{l}71 \text { (65.1\%) } \\
38 \text { (34.9\%) }\end{array}$ & $\begin{array}{l}94(47.5 \%) \\
104(52.5 \%)\end{array}$ & 0.003 \\
\hline
\end{tabular}

Note: Bold indicates statistical significance.

participants, respectively. This is in contrast to previous studies which had targeted LDL-C levels in 50\%-66\% of their participants. ${ }^{18,64,70-72}$ Hypertriglyceridemia was the only lipoprotein significantly different between HIVinfected and HIV-negative participants highlighting the possibility of diabetes mellitus playing a significant role in defective lipoprotein metabolism in both groups. The significantly high level of triglycerides among HIVinfected participants on HAART as compared to HIV- negative participants has also been observed in previous studies. ${ }^{54}$ There is a possibility of HAART contributing selectively to hypertriglyceridemia; however, this remains to be substantiated with a prospective study given the cross-sectional nature of our study.

Despite having a high proportion of patients not reaching target LDL-C levels, only a quarter of our participants were on statins which is a concern. This compares to findings of Mwita et al in the same clinic in Botswana who found $45.5 \%$ of eligible diabetes patients were on statins. ${ }^{73}$ Our findings are also worse than those of diabetic HIV-infected patients in Tanzania where approximately one-third of patients were on statins. Our results emphasize the need to remind physicians even in a tertiary care setting on the importance of prescribing statins to reduce LDL-C levels and subsequent cardiovascular events in eligible patients, and we will be following this up.

In our study, female gender was also significantly associated with not reaching target HDL-C levels by ADA criteria. This is similar to findings in some studies ${ }^{19,53}$ but contradicts the findings of others which consistently showed a high likelihood of women being within target HDL-C compared to men. ${ }^{64,72,74}$ We are not sure of the reasons behind these differences, but will be exploring this further.

Finally, our study also revealed that $34.2 \%$ of HIVinfected diabetic participants were obese. This is similar to the findings of a study in the USA which found $38.2 \%$ of HIV patients were obese. ${ }^{75}$ HIV-negative diabetic participants had a significantly higher prevalence of obesity $(52.5 \%)$. This is not surprising given that a previous study in Botswana using the same cut-off point for BMI in the same city found a prevalence of $65.5 \%$ among patients attending a private hospital medical clinic year 2005 to $2015 .^{76}$ However, our results indicate a higher prevalence of obesity compared to the general population in Botswana. According to the Botswana Demographic Survey of 2017 , obesity accounted for $10.9 \%$ of the surveyed population. $^{77}$

\section{Strengths and Limitations}

Our study has several strengths and limitations. It is the first study in Botswana to evaluate the prevalence of metabolic syndrome and individual metabolic control variables among a population of diabetic patients with HIVinfection. The study adds to the body of literature not well studied in SSA and provides an opportunity for future prospective and intervention studies in the area of 
metabolic control and associated complications. However, the cross-sectional nature of this study cannot provide causal relationships rather only associations; similarly, the bivariate analysis in this study cannot control for confounding variables emphasizing the need for future prospective studies. The study was also conducted in a tertiary setting whose patients' characteristics may differ from those in the primary/secondary care settings. Despite these limitations, we believe this study has found valuable findings which we are taking forward in our clinic.

\section{Conclusion}

Overall, the metabolic syndrome is an appreciable problem in this leading tertiary diabetic clinic in Botswana among both HIV-infected and HIV-negative participants, with the presence of the metabolic syndrome significantly associated with older age and female gender. Future prospective studies are warranted in our setting and similar SSA settings to enhance the understanding of the role played by HAART in causing the metabolic syndrome. In the meantime interventions such as reminding physicians to regularly assess for individual metabolic control variables in their patients and act accordingly in a multidisciplinary approach involving pharmacotherapy is warranted including increasing use of statins as well as encouraging regular exercise and improved diet. There is also a need to devise programmes specific for diabetic HIV-infected and HIV-negative participants in Botswana to curb the worrying trend of obesity, and we will be following this up.

\section{Data Sharing Statement}

The data set generated and/or analyzed during this study are included in this submitted manuscript and is available from the corresponding author on reasonable request.

\section{Ethical Approval}

Ethical approval to conduct the study was obtained from the University of Botswana Institutional Review Board, Ministry of Health and Princess Marina Hospital Institutional Review Boards. The study adhered to the principles of Declaration of Helsinki.

\section{Acknowledgments}

We would like to thank the study participants for voluntarily participating in this study, staff of Block 6 diabetic clinic and Princess Marina Hospital in Gaborone, Botswana for cooperation throughout the study and our data collectors; Mrs Tebogo Eyman Mudojwa and Ms Lydiah Mtande for their dedication.

\section{Funding}

The study was funded by Office of Research and Development (ORD) of the University of Botswana (Grant Project Number: R1210).

\section{Disclosure}

All authors declare no conflicts of interest for this work.

\section{References}

1. Assah F, Mbanya JC. Diabetes mellitus in sub- Saharan Africa. In: Diabetes Mellitus in Developing Countries and Underserved Communities. Cham: Springer; 2017:33-48. doi:10.1007/978-3-31941559-8_3

2. IDF. Diabetes atlas Ninth edition. 2019. Available from: https://www. diabetesatlas.org/upload/resources/2019/IDF_Atlas_9th_Edition 2019.pdf. Accessed October 5, 2020.

3. World Bank indicators. Botswana - diabetes prevalence (\% of population ages 20 to 79). Available from: https://tradingeconomics.com/ botswana/diabetes-prevalence-percent-of-population-ages-20-to-79wb-data.html. Accessed October 5, 2020

4. International Diabetes Federation. IDF Diabetes Atlas. 7th ed. Brussels, Belgium: International Diabetes Federation; 2015. Available from: http://www.diabetesatlas.org. Accessed December 29, 2020.

5. Moyo D, Tanthuma G, Mushisha O, et al. Diabetes mellitus in HIV-infected patients receiving antiretroviral therapy. S Afr Med J. 2014;104(1):37-39. doi:10.7196/SAMJ.6792

6. Godman B, Basu D, Pillay Y, et al. Ongoing and planned activities to improve the management of patients with Type 1 diabetes across Africa; implications for the future. Hosp Pract. 2020;48(2):51-67. doi:10.1080/21548331.2020.1745509

7. Godman B, Basu D, Pillay Y, et al. Review of ongoing activities and challenges to improve the care of patients with type 2 diabetes across Africa and the implications for the future. Front Pharmacol. 2020;11:108. doi:10.3389/fphar.2020.00108

8. American Diabetes Association. Standards of medical care in diabetes. Diabetes Care. 2017;40(1):S1-S2. doi:10.2337/dc17-S001

9. Satlin MJ, Hoover DR, Glesby MJ. Glycemic control in HIV-infected patients with diabetes mellitus and rates of meeting American Diabetes Association Management Guidelines. AIDS Patient Care STDS. 2011;25(1):5-12. doi:10.1089/apc.2010.0237

10. Van Vugt M, Hamers R, Schellekens O, Rinke de Wit T, Reiss P. Diabetes and HIV/AIDS in sub-Saharan Africa: the need for sustainable healthcare systems. Diabetes Voice. 2007;52(3):23-26.

11. So-Armah K, Freiberg MS. HIV and cardiovascular disease: update on clinical events, special populations, and novel biomarkers. Curr HIV/AIDS Rep. 2018;15(3):233-244. doi:10.1007/s11904-018-04005

12. Temu TM, Kirui N, Wanjalla C, et al. Cardiovascular health knowledge and preventive practices in people living with HIV in Kenya. BMC Infect Dis. 2015;15(1):421. doi:10.1186/s12879-015-1157-8

13. Pillay S, Aldous C, Mahomed F. A deadly combination - HIV and diabetes mellitus: where are we now? S Afr Med J. 2016;106 (4):378-382. doi:10.7196/SAMJ.2016.v106i4.9950

14. Zuniga J, Nguyen ML, Holstad M. Predictors of dual control of HIV and diabetes. Aids Care. 2016;28(9):1124-1127. doi:10.1080/ 09540121.2016.1139667 
15. Adeyemi O, Vibhakar S, Are MB. We meeting the american diabetes association goals for HIV-infected patients with diabetes mellitus? Clin Infect Dis. 2009;49:799-802. doi:10.1086/605286

16. Bury JE, Stroup JS, Stephens JR, et al. Achieving American Diabetes Association goals in HIV-seropositive patients with diabetes mellitus. Baylor University Medical Center Proc. 2007;20:118-123. doi:10.1080/08998280.2007.11928265

17. Davies ML, Johnson MD, Brown JN, Bryan WE, Townsend ML. Predictors of glycemic control among HIV-positive veterans with diabetes. Int $J$ STD AIDS. 2015;26(4):262-267. doi:10.1177/ 0956462414535207

18. Maganga E, Smart LR, Kalluvya S, et al. Glucose metabolism disorders, HIV and antiretroviral therapy among Tanzanian Adults. PLoS One. 2015;10(8):e0134410. doi:10.1371/journal.pone.0134410

19. Sales S, Campa A, Makhema J, et al. Metabolic syndrome in HIV + asymptomatic adults in Botswana, Africa. FASEB J. 2009;918:4.

20. Sodorenkov O, Nilssen O, Grjibovski AM. Metabolic syndrome in Russian adults: associated factors and mortality from cardiovascular diseases and all causes. BMC Public Health. 2010;10:582. doi:10.1186/1471-2458-10-582

21. HIV Treatment and Care. Available from: https:/www.cdc.gov/hiv/clin icians/treatment/treatment-clinicians.html. Accessed October 5, 2020.

22. Kalra S, Kalra B, Agrawal N, Unnikrishnan AG. Understanding diabetes in patients with HIV/AIDS. Diabetol Metab Syndr. 2011;3:2. doi:10.1186/1758-5996-3-2

23. Young F, Critchley J, Johnstone LC, Unwin NC. A review of co-morbidity between infectious and chronic disease in sub Saharan Africa: TB and diabetes mellitus, HIV and metabolic syndrome, and the impact of globalization. Global Health. 2009;5:9. doi:10.1186/ 1744-8603-5-9

24. Lo J. Dyslipidemia and lipid management in HIV-infected patients. Curr Opin Endocrinol Diabetes Obes. 2011;18(2):144-147. doi:10.1097/MED0b013e328344556e

25. Grunfeld C, Pang M, Doerrler W, et al. Lipids, lipoproteins, triglyceride clearance, and cytokines in human immunodeficiency virus infection and the acquired immunodeficiency syndrome. J Clin Endocrinol Metab. 1992;74:1045-1052. doi:10.1210/jcem.74.5.1373735

26. Gutierrez AD, Balasubramanyam A. Dysregulation of glucose metabolism in HIV patients: epidemiology, mechanisms and management. Endocrine. 2012;41(1):1-10. doi:10.1007/s12020-011-9565-z

27. Quin J. Diabetes and HIV. Clin Med (Northfield Il). 2014;14 (6):667-669. doi:10.7861/clinmedicine.14-6-667

28. McAIpine RR, Morris AD, Emslie- Smith A, et al. The annual incidence of diabetic complications in a population of patients with type I and type 2 diabetes. Diabet Med. 2005;22:348-352. doi:10.1111/j.1464-5491.2004.01391.x

29. Stratton IM, Adler AI, Nell HA, et al. Association of glycaemia with macrovascular and microvascular complications of type 2 diabetes (UKPDS 35): prospective observational study. BMJ. 2000;321:405-412. doi:10.1136/bmj.321.7258.405

30. Khaw IC, Wareham N, Luben R, et al. Glycated hemoglobin, diabetes, and mortality in men in Norfolk cohort of European prospective investigation of cancer and nutrition (EPIC-Norfolk). BMJ. 2001;322:15-18. doi:10.1136/bmj.322.7277.15

31. Kuusisto J, Mykkanen L, Pyorala K, Laakso M. NIDDM and its metabolic control predict coronary heart disease in elderly subjects. Diabetes. 1994;43:960-967. doi:10.2337/diab.43.8.960

32. Klein R. Hyperglycemia and microvascular and macrovascular disease in diabetes. Diabetes Care. 1995;18:258-268. doi:10.2337/ diacare.18.2.258

33. United Kingdom Prospective Diabetes Study Group. United Kingdom Prospective Diabetes Study 24: a 6-year, randomized, controlled trial comparing sulfonylurea, insulin, and metformin therapy in patients with newly diagnosed type 2 diabetes that could not be controlled with diet therapy. Ann Intern Med. 1998;128:165-175. doi:10.7326/0003-4819-128-3-199802010-00001
34. UNAIDS. Prevention gap report. 2016. Available from: https://www. avert.org/professionals/hiv-around-world/sub-saharan-africa/bots wana. Accessed October 5, 2020.

35. HIV/AIDS. UNDP in Botswana. Available from: http://www.bw. undp.org/content/botswana/en/home/ourwork/hiv_aids/overview. html. Accessed August 25, 2020.

36. Ogunleye OO, Basu D, Mueller D, et al. Response to the novel corona virus (COVID-19) pandemic across Africa: successes, challenges, and implications for the future. Front Pharmacol. 2020;11:1205. doi:10.3389/fphar.2020.01205

37. Kluge HHP, Wickramasinghe K, Rippin HL, et al. Prevention and control of non-communicable diseases in the COVID-19 response. Lancet. 2020;395(10238):1678-1680. doi:10.1016/S0140-6736(20) 31067-9

38. Basu S. Non-communicable disease management in vulnerable patients during Covid-19. Indian J Med Ethics. 2020;V(2):103-105. doi:10.20529/IJME.2020.041

39. Fleiss JL, Levin B, Paik MC. Statistical Methods for Rates and Proportions, Formulas. John wiley \& sons; 2013.

40. Radikara N. The prevalence of chronic kidney disease and associated factors among adult patients with Type 2 diabetes mellitus who attend the diabetes centre in Gaborone, Botswana Stellenbosch University. 2017. Available from: http://scholar.sun.ac.za/handle/10019.1/ 101485. Accessed December 29, 2020.

41. World Health Organization. WHO STEPS instrument. Geneva, Switzerland: World Health Organization; 2011. Available from: http://apps.who.int/iris/bitstream/10665/43588/1/9241594934_eng. pdf. Accessed December 29, 2020.

42. Mendes PM, Zamberlan EC. Análise do consumo alimentar determinado pela aquisição domiciliar no Brasil. Rev Univ Vale Do Rio Verde (Três Corações). 2013;7:336-345. doi:10.5892/860

43. WHO. Global strategy for the prevention and control of noncommunicable diseases. Geneva: World Health Organization (WHO); 2000b

44. Waist circumference and waist-hip ratio: report of a WHO expert consultation. Geneva; December 8-11, 2008. Available from: https:// apps.who.int/iris/bitstream/handle/10665/44583/9789241501491_ eng.pdf?ua=1. Accessed August 25, 2020.

45. World Health Organization. WHO STEPS Instrument. Geneva, Switzerland: World Health Organization; 2011.

46. The IDF consensus worldwide definition of the metabolic syndrome. Available from: https://www.pitt.edu/ super1/Metabolic/IDF1.pdf. Accessed August 25, 2020.

47. American Diabetes Association. Standards of medical care in diabetes-2019 Abridged for primary care providers. Clin Diabetes. 2019;37(1):11-34. doi:10.2337/cd18-0105

48. SEMDSA Type 2 Diabetes Guidelines Expert Committee. SEMDSA 2017 guidelines for the management of type 2 diabetes mellitus. JEMDSA. 2017;22(1):S1-S196.

49. WMA DECLARATION OF HELSINKI. ETHICAL PRINCIPLES FOR MEDICAL RESEARCH INVOLVING HUMAN SUBJECTS. Available from: https://www.wma.net/policies-post/wma-declarationof-helsinki-ethical-principles-for-medical-research-involving-humansubjects/. Accessed September 19, 2020.

50. Husain NE, Noor SK, Elmadhoun WM, et al. Diabetes, metabolic syndrome and dyslipidemia in people living with HIV in Africa: re-emerging challenges not to be forgotten. HIV Aids (Auckl). 2017;9:193-202. doi:10.2147/HIV.S137974

51. Nguyen KA, Peer N, Mills EJ, Kengne AP. A meta-analysis of the metabolic syndrome prevalence in the global HIV-infected population. PLoS One. 2016;11(3):e0150970. doi:10.1371/journal. pone. 0150970

52. Bhatti GK, Bhadada SK, Vijayvergiya R, Mastana SS, Bhatti JS. Metabolic syndrome and risk of major coronary events among the urban diabetic patients: North Indian diabetes and cardiovascular disease study-NIDCVD-2. J Diabetes Complications. 2016;30 (1):72-78. doi:10.1016/j.jdiacomp.2015.07.008 
53. Nanda Kumar LG, Kaveri NK, Anmol MNY. Metabolic syndrome: a clinic based rural study-are women at high risk? Diabetes Metab Syndr. 2011;5(2):81-84. doi:10.1016/j.dsx.2012.02.016

54. Mondy K, Overton ET, Grubb J, et al. Metabolic syndrome in HIV-infected patients from an urban, Midwestern US outpatient population. Clin Infect Dis. 2007;44(5):726-734. doi:10.1086/511679

55. Sobieszczyk ME, Werner L, Mlisana K, et al. Metabolic syndrome after HIV acquisition in South African women. J Acquir Immune Defic Syndr. 2016;73(4):438-445. doi:10.1097/QAI.0000000000001123

56. Guira O, Tiéno H, Diendéré AE, et al. Features of metabolic syndrome and its associated factors during highly active antiretroviral therapy in Ouagadougou (Burkina Faso). J Int Assoc Provid AIDS Care. 2016;15(2):159-163. doi:10.1177/2325957415601503

57. Tesfaye DY, Kinde S, Medhin G, et al. Burden of metabolic syndrome among HIV-infected patients in Southern Ethiopia. Diabetes Metab Syndr. 2014;8(2):102-107. doi:10.1016/j.dsx.2014.04.008

58. Sears S, Buendia JR, Odem S, et al. Metabolic syndrome among people living with HIV receiving 545 medical care in Southern United States: prevalence and risk factors. AIDS Behav. 2019;23 (11):2916-2925. doi:10.1007/s10461-019-02487-8

59. Zannou DM, Denoeud L, Lacombe K, et al. Incidence of lipodystrophy and metabolic disorders in patients starting non-nucleoside reverse transcriptase inhibitors in Benin. Antivir Ther. 2009;14:371-380.

60. Kiage JN, Heimburger DC, Nyirenda CK, et al. Cardiometabolic risk factors among HIV patients on antiretroviral therapy. Lipids Health Dis. 2013;12:50. doi:10.1186/1476-511X-12-50

61. Fleishman A, Johnsen S, Systrom DM, et al. Effects of a nucleoside reverse transcriptase inhibitor, Stavudine, on glucose disposal and mitochondrial function in muscle of healthy adults. Am J Physiol Endocrinol Metab. 2007;292:E1666- E1673. doi:10.1152/ajpendo.00550.2006

62. Ministry of Health Botswana. HIV clinical care guidelines. 2016. Available from: http://www.moh.gov.bw/Publications/Handbook HIV_treatment_guidelines.pdf. Accessed September 26, 2020.

63. Quercia R, Roberts J, Martin-Carpenter L, Zala C. Comparative changes of lipid levels in treatment-naive, HIV-1-infected adults treated with dolutegravir vs efavirenz, raltegravir, and ritonavir-boosted darunavir-based regimens over 48 weeks. Clin Drug Investig. 2015;35(3):211-219. doi:10.1007/s40261-014-0266-2

64. Clayden P. Dolutegravir-based first-line non-inferior to efavirenz-based ART but associated with substantial weight gain: results from the ADVANCE study. HTB 2019.

65. Hoerger TJ, Segel JE, Gregg EW, Saaddine JB. Is glycemic control improving in U.S. adults? Diabetes Care. 2008;31:81-86. doi:10.2337/ dc07-1572

66. Brown TT, Cole SR, Li X, et al. Antiretroviral therapy and the prevalence and incidence of diabetes mellitus in the multicenter AIDS cohort study. Arch Intern Med. 2005;165:1179-1184. doi:10.1001/archinte.165.10.1179
67. Brown TT, Li X, Cole SR, et al. Cumulative exposure to nucleoside analogue reverse transcriptase inhibitors is associated with insulin resistance markers in the multicenter AIDS cohort study. AIDS. 2005;19:1375-1383. doi:10.1097/01.aids.0000181011.62385.91

68. Awotedu K, Ekpebegh C, Longo-Mbenza B, Iputo J. Prevalence of metabolic syndrome assessed by IDF and NCEP ATP 111 criteria and determinants of insulin resistance among HIV patients in the Eastern Cape Province of South Africa. Diabetes Metab Syndr Clin Res Rev. 2010;4:210-214. doi:10.1016/j.dsx.2010.09.002

69. Thompson V, Medard B, Taseera K, et al. Regional anthropometry changes in antiretroviral-naïve persons initiating a Zidovudinecontaining regimen in Mbarara, Uganda. AIDS Res Hum Retroviruses. 2011;27:785-791. doi:10.1089/AID.2010.0272

70. Hattingh Z, Walsh C. The metabolic profiles of HIV-infected and non-infected women in Mangaung, South Africa. South Afr J Clin Nutr. 2009;22:23-28. doi:10.1080/16070658.2009.11734213

71. Kirk JK, Huber KR, Clinch CR. Attainment of goals from national guidelines among persons with type 2 diabetes: a cohort study in an academic family medicine setting. NC Med J. 2005;66:415-419.

72. Putzer G, Roetzheim R, Ramirez AM, Sneed K, Brownlee HJ, Campbell RJ. Compliance with recommendations for lipid management among patients with type 2 diabetes in an academic family practice. J Am Board Fam Pract. 2004;17:101-107. doi:10.3122/jabfm.17.2.101

73. Mwita JC, Godman B, Esterhuizen TM. Statin prescription among patients with type 2 diabetes in Botswana: findings and implications. BMC Endocr Disord. 2020;20(1):36. doi:10.1186/s12902-020-0516-7

74. Ferrara A, Mangione CM, Kim C, et al. Sex disparities in control and treatment of modifiable cardiovascular disease risk factors among patients with diabetes: translating research into action for diabetes (TRIAD) study. Diabetes Care. 2008;31:69-74. doi:10.2337/dc07-1244

75. Lichtenstein KA, Armon C, Buchacz K, et al. Provider compliance with guidelines for management of cardiovascular risk in HIV-infected patients. Prev Chronic Dis. 2013;10:E10. doi:10.5888/ pcd10.120083

76. Onen CL. Obesity in Botswana: time for new cut-off points for abdominal girth? Cardiovasc J Afr. 2017;28(2):86-91. doi:10.5830/ CVJA-2016-060

77. Botswana demographic survey report. 2017. Available from: http://www.statsbots.org.bw/sites/default/files/publications/ Botswana\%20Demographic\%20Survey\%20Report\%202017.pdf. Accessed September 262020.

\section{Publish your work in this journal}

Diabetes, Metabolic Syndrome and Obesity: Targets and Therapy is an international, peer-reviewed open-access journal committed to the rapid publication of the latest laboratory and clinical findings in the fields of diabetes, metabolic syndrome and obesity research. Original research, review, case reports, hypothesis formation, expert opinion and commentaries are all considered for publication. The manuscript management system is completely online and includes a very quick and fair peer-review system, which is all easy to use. Visit http://www.dovepress.com/testimonials.php to read real quotes from published authors. 